\title{
Oncogenic potential of macrophage-capping protein in clear cell renal cell carcinoma
}

\author{
ZHUANG-FEI CHEN $^{1}$, ZE-HAI HUANG ${ }^{1}$, SHI-JUN CHEN ${ }^{1}$, \\ YAO-DONG JIANG ${ }^{1}$, ZI-KE QIN ${ }^{2}$, SHAO-BIN ZHENG ${ }^{1}$ and TONG CHEN ${ }^{1}$ \\ ${ }^{1}$ Department of Urology, Nanfang Hospital, Southern Medical University, \\ Guangzhou, Guangdong 510515; ${ }^{2}$ Department of Urology, Cancer Center, Sun Yat-Sen University and \\ State Key Laboratory of Oncology in Southern China, Guangzhou, Guangdong 510060, P.R. China
}

Received August 31, 2019; Accepted September 15, 2020

DOI: $10.3892 / \mathrm{mmr} .2020 .11718$

\begin{abstract}
Macrophage-capping protein (CapG) is a newly characterized oncogene involved in several types of cancer. However, the expression patterns and biological mechanisms of CapG in clear cell renal cell carcinoma (ccRCC) are unclear. The present study aimed to investigate the roles of CapG in the prognosis, proliferation and metastasis of ccRCC. In the present study, the expression of CapG was analyzed by western blotting in 24 paired ccRCC and adjacent normal tissue samples. Another 152 tissue samples from 152 patients with ccRCC were examined by immunohistochemistry. Compared with normal tissue, CapG expression was significantly increased in ccRCC tissue, and high CapG expression was associated with advanced tumor stage, histological grade, lymph node metastasis, and poor overall survival. Moreover, CapG was an independent predictor of survival. Lentivirus-mediated CapG knockdown significantly inhibited 786-O cell proliferation, migration, and invasion, induced cell cycle arrest at the $\mathrm{G}_{2} / \mathrm{M}$ phase, and increased apoptosis in vitro. Microarray analysis indicated that RAC, CDC42 and ERK/MAPK signaling were disrupted by CapG knockdown in 786-O cells. In conclusion, the present findings indicate that $\mathrm{CapG}$ plays an oncogenic role in ccRCC and may represent a potential therapeutic target for this disease.
\end{abstract}

\section{Introduction}

Renal cell carcinoma (RCC) accounts for 2-3\% of all adult malignancies, and the most common subtype of RCC is clear cell RCC (ccRCC) (1). Moreover, $20-30 \%$ of patients have locally advanced or metastatic disease at the time of diagnosis,

Correspondence to: Professor Tong Chen, Department of Urology, Nanfang Hospital, Southern Medical University, 1838 North Guangzhou Avenue, Guangzhou, Guangdong 510515, P.R. China E-mail: chentonguro@163.com

Key words: macrophage capping protein, renal cell carcinoma, clear cell, prognosis, migration, invasion and about $20-30 \%$ of patients with localized disease who are treated eventually relapse $(2,3)$. Although several targeted therapies have been approved for the treatment of advanced or metastatic RCC, these treatments are associated with limited overall survival (OS) if resistance to therapy occurs $(4,5)$. Thus, validated biomarkers for diagnosis, prognosis, and disease monitoring during therapy, as well as potential therapeutic targets are urgently needed.

In our previous study on tumor-specific changes in the proteome of ccRCC, macrophage-capping protein (CapG) was differentially expressed in ccRCC, compared with paired healthy tissue (6). CapG is an actin-binding protein of the gelsolin superfamily that serves a crucial role for the organization of the actin cytoskeleton (7). Although CapG only contains three gelsolin-like domains and can bind and cap actin filaments in the presence of calcium, it does not sever filaments (8). Previous studies have confirmed that CapG expression is elevated in several types of cancer, such as pancreatic cancer (9) and breast cancer (10). High CapG expression is associated with tumor progression and metastasis in gastric cancer (11). However, the expression pattern and function of CapG in ccRCC remain to be investigated.

Therefore, the aim of this study was to evaluate the expression levels of CapG in ccRCC and adjacent normal tissue and to determine whether CapG expression was associated with clinicopathological characteristics and OS. In addition, the function of CapG was also examined in ccRCC cell lines.

\section{Materials and methods}

Patients and tissue samples. Matched ccRCC and normal tissue samples were obtained from 24 patients with ccRCC at the Department of Urology, Southern Medical University Nanfang Hospital, between February 2010 and July 2010. The patients included 15 males and 9 females aged 41-73 years (median, 58 years). Tissue samples were frozen in liquid nitrogen within 20 min after surgery and stored in liquid nitrogen until use. All tissue samples were examined by certified pathologists at the hospital. In addition, 152 paraffin-embedded specimens of ccRCC and 40 specimens of adjacent normal tissue were collected between January 1999 and August 2002 for immunohistochemistry (IHC) analysis. The median survival time 
of the 152 patients was 89 months, and the follow-up duration ranged from 4 to 131 months. This study was approved by The Ethics Committee of Southern Medical University Nanfang Hospital, and all patients provided informed consent for the treatments, and to have their data used for research purposes.

Western blot. The tissues samples were lysed in RIPA lysis buffer (cat. no. P0013B; Beyotime Insitute of Biotechnology). Protein concentration was determined using a Bicinchoninic Acid Protein Assay kit (cat. no. P0010S; Beyotime Institute of Biotechnology) according to the manufacturer's protocol. Western blot for proteins expression were performed. Briefly, $40 \mu \mathrm{g}$ of lysates were separated via $12 \%$ SDS-PAGE, and transferred to PVDF membranes (EMD Millipore). The membrnes were blocked with 5\% non-fat dry milk for $2 \mathrm{~h}$ at room temperature, and then incubated with primary goat polyclonal anti-CapG antibody (1:200; cat. no. sc-33084; Santa Cruz Biotechnology, Inc.) overnight at $4^{\circ} \mathrm{C}$. Subsequently, the membranes were incubated with a horseradish peroxidase-conjugated rabbit anti-goat IgG secondary antibody (cat. no. ZB-2306; 1:5,000; OriGene Technologies, Inc.) for $1.5 \mathrm{~h}$ at room temperature. $\beta$-actin was used as internal loading control (1:1,000; cat. no. ab8229; Abcam). Signals were visualized with ECL detection reagent (Thermo Fisher Scientific, Inc.). Protein bands were scanned and analyzed using a Gel-Pro analyzer (version 4.0; Media Cybernetics, Inc.). All samples were set up in triplicate in every experiment.

IHC. IHC procedures were performed using an SP-9000 detection kit (OriGene Technologies, Inc.) according to the manufacturer's protocol. Briefly, tissue samples were fixed in $10 \%$ neutral formalin for $24 \mathrm{~h}$ at room temperature and embedded in paraffin, which were cut into $4-\mu \mathrm{m}$ sections and placed in a $37^{\circ} \mathrm{C}$ incubator for $120 \mathrm{~min}$. Subsequently, tissue sections were deparaffinized with xylene at room temperature for $20 \mathrm{~min}$ and rehydrated using a descending ethanol series (100, 100, 95 and $70 \%$ ethanol). Sections were submerged into EDTA antigenic retrieval buffer and microwaved for antigenic retrieval. The sections were then treated with $3 \%$ hydrogen peroxide in methanol to quench the endogenous peroxidase activity, followed by incubation with normal goat serum (cat. no. SP9000; OriGene Technologies, Inc.) for $15 \mathrm{~min}$ at room temperature to block the nonspecific binding. CapG was detected using a goat polyclonal antibody against CapG (1:100; cat. no. sc-33084; Santa Cruz Biotechnology, Inc.) overnight at $4^{\circ} \mathrm{C}$. In the negative control group, the primary antibody was replaced with primary antibody diluent (cat. no. ZLI-9029; OriGene Technologies, Inc.) in blocking buffer. After washing with PBS, the tissue sections were treated with biotinylated anti-goat secondary antibody (cat. no. SP9000; OriGene Technologies, Inc.) for $15 \mathrm{~min}$ at room temperature, followed by further incubation with a horseradish peroxidase-labeled streptavidin (cat. no. SP9000; OriGene Technologies, Inc.) for $15 \mathrm{~min}$ at room temperature. The tissue sections were stained with 3,3'-diaminobenzidine (cat. no. ZLI-9033; OriGene Technologies, Inc.) for $3 \mathrm{~min}$ at room temperature, counterstained with $10 \%$ Mayer's hematoxylin for $30 \mathrm{sec}$ at room temperature, dehydrated and mounted in Crystal Mount. The slides were observed using a light microscope (Olympus Corporation; magnification, x200).
The proportion of cells expressing CapG varied from 0 to $100 \%$, scored as 1 ( $\leq 10 \%), 2(11-50 \%), 3(51-75 \%)$ or $4(\geq 76 \%)$, and the intensity of immunostaining varied from weak to strong, scored as 1 (no staining), 2 (weak staining), 3 (moderate staining) or 4 (strong staining). The final score was calculated as the proportion of cells multiplied by the staining intensity. A final score $>8$ classified tumors into the high-expression group, whereas a score $\leq 8$ classified tumors into the low-expression group. Each section was assessed by two independent experienced pathologists and a third pathologist made the final decision when two pathologists were not in agreement.

Cell lines and cell culture conditions. The human 786-O ccRCC cell line was obtained from the Institute of Urology, Southern Medical University. The cells were maintained in RPMI-1640 medium (HyClone; GE Healthcare Life Sciences) with $25 \mathrm{mM}$ glucose, 10\% fetal calf serum (Gibco; Thermo Fisher Scientific, Inc.), $100 \mathrm{U} / \mathrm{ml}$ penicillin, and $100 \mu \mathrm{g} / \mathrm{ml}$ streptomycin at $37^{\circ} \mathrm{C}$ in a humidified atmosphere containing $5 \% \mathrm{CO}_{2}$.

Lentivirus vector siRNA construction. For CapG knockdown, three small interfering RNAs (siRNAs; siRNA1, 5'-CCA ACATCCTGGAACGCAA-3'; siRNA2, 5'-CGAATGAGA AGGAGCGGCA-3'; and siRNA3, 5'-GGAAGGTGGTGT GGAGTCA-3') specifically targeting CapG were designed, synthesized and individually subcloned into the GV248 plasmid (Shanghai GeneChem Co., Ltd.). For lentivirus packaging, $5 \times 10^{6} 239 \mathrm{~T}$ cells were seeded onto a $10-\mathrm{cm}$ culture dish and incubated with complete Dulbecco's modified Eagle's medium (HyClone; GE Healthcare Life Sciences) for $24 \mathrm{~h}$, followed by transfection with $20 \mu \mathrm{g} \mathrm{GV} 248-C a p G-s i R N A$ plasmid and two helper plasmids (helper 1.0, $15 \mu \mathrm{g}$; helper 2.0, $10 \mu \mathrm{g}$; Shanghai GeneChem Co., Ltd.) using Lipofectamine ${ }^{\circledR}$ 2000 (Invitrogen; Thermo Fisher Scientific, Inc.) according to the manufacturer's instructions. After $48 \mathrm{~h}$, the viral supernatant was purified by ultracentrifugation at $75,555 \mathrm{x} \mathrm{g}$ at $4^{\circ} \mathrm{C}$ for $2 \mathrm{~h}$. The resulting pellet was resuspended in PBS and centrifugated at $9,600 \times \mathrm{g}$ at $4^{\circ} \mathrm{C}$ for $5 \mathrm{~min}$. The supernatant was collected. The most effective double-stranded CapG-targeting siRNA sequence (siRNA1; 5'-CCAACATCCTGGAACGC AA-3'; referred to as CapG-siRNA thereafter) was synthesized and cloned into the pGCSIL-GFP vector by Shanghai GeneChem Co., Ltd. An siRNA sequence with no homology to any known human gene (5'-TTCTCCGAACGTGTCACGT-3') was used to generate the negative control (NC) lentiviral vector. For lentiviral transduction, 786-O cells were plated in 6 -well plates at a density of $5 \times 10^{4}$ cells $/ \mathrm{ml}$ until cell confluence reached $30 \%$. Lentivirus with an MOI of 5 and $5 \mu \mathrm{g} / \mathrm{ml}$ of polybrene (Shanghai GeneChem Co. Ltd.) were then added.

$R N A$ isolation and reverse transcription-quantitative (RT-q) $P C R$. Lentivirus siRNA knockdown efficiency was determined by RT-qPCR. Cells were harvested, and total RNA was extracted with TRIzol ${ }^{\circledR}$ reagent (Invitrogen Thermo Fisher Scientific, Inc.) according to the manufacturer's protocol. Reverse transcription was performed using M-MLV reverse transcriptase (Promega Corporation) and oligo-dT primers (Sangon Biotech Co., Ltd.) to obtain cDNA. The RT tempera- 
ture protocol was $42^{\circ} \mathrm{C}$ for $60 \mathrm{~min}$ and $70^{\circ} \mathrm{C}$ for $10 \mathrm{~min}$, followed by maintenance at $-20^{\circ} \mathrm{C}$ until qPCR analysis. CapG mRNA expression was determined with RT-qPCR using SYBR Green master mix (Takara Bio, Inc.) on a TP80 RT-PCR instrument TP800 (Takara Bio, Inc.). The thermocycling conditions were as follows: Initial denaturation at $95^{\circ} \mathrm{C}$ for $30 \mathrm{sec}$; followed by 40 cycles of denaturation at $95^{\circ} \mathrm{C}$ for $5 \mathrm{sec}$ and $60^{\circ} \mathrm{C}$ for $30 \mathrm{sec}$; dissociation at $95^{\circ} \mathrm{C}$ for $15 \mathrm{sec}$, $60^{\circ} \mathrm{C}$ for $30 \mathrm{sec}$ and $95^{\circ} \mathrm{C}$ for $15 \mathrm{sec}$. The primers used were: i) GAPDH forward, 5'-TGACTTCAACAGCGACACCCA-3'; ii) GAPDH reverse, 5'-CACCCTGTTGCTGTAGCCAAA-3'; iii) CapG forward, 5'-GCAGCTCTGTATAAGGTCTCTG-3'; and iv) CapG reverse, 5'-TTTCGCCCCTTCCAGATATAG-3'. Relative CapG expression was normalized to GAPDH, and data analysis was conducted using the $2^{-\Delta \Delta \mathrm{Cq}}$ method (12).

Cell proliferation assay. The 786-O cells were seeded in 96-well plates to examine cell proliferation using a Cell Counting Kit-8 (CCK-8) proliferation assay (cat. no. 96992; Sigma Aldrich; Merck KGaA) according to the manufacturer's guidelines. Cells were transduced with CapG-siRNA lentivirus or NC lentivirus and incubated for 24, 48, 72, 96 and $120 \mathrm{~h}$, then treated with CCK-8 for $4 \mathrm{~h}$. Optical density (OD) was measured at $450 \mathrm{~nm}$ using an M2009PR automatic microplate reader (Tecan Infinite). OD450/fold was calculated as the sum of day 1-day 5 OD450 values relative to the day 1 OD450 value in each group.

Cell cycle analysis by flow cytometry. The 786-O cells were transduced with CapG-siRNA lentivirus or NC lentivirus. After incubation for $72 \mathrm{~h}$, cell suspensions were generated and plated in $6-\mathrm{cm}$ dishes for further culture. After reaching $\sim 80 \%$ coverage, cells were collected and fixed with pre-chilled $70 \%$ alcohol for at least $1 \mathrm{~h}$. Cells were then washed with PBS, and incubated in dark at $4^{\circ} \mathrm{C}$ for $30 \mathrm{~min}$ with propidium iodide (PI; cat. no. P4170; Sigma-Aldrich; Merck KGaA) buffer containing 40X PI stock solution ( $2 \mathrm{mg} / \mathrm{ml}), 100 X$ RNase stock solution $(10 \mathrm{mg} / \mathrm{ml})$, and $1 \mathrm{X}$ PBS at a ratio of 25:10:1,000. Cell cycle analysis was performed using a flow cytometer (Guava EasyCyte HT; EMD Millipore), and at least $1 \times 10^{6}$ cells per sample were used in each experiment. Data were analyzed using ModFit software (version LT 4.1; Verity Software House, Inc.).

Annexin V-allophycocyanin (APC) apoptosis assay. An Annexin V-APC apoptosis detection kit (cat. no. 88-8007; eBioscience) was used for cell apoptosis analysis, according to the manufacturer's instructions. After lentiviral infection, cells were incubated for $120 \mathrm{~h}$, harvested, washed with PBS buffer, and resuspended in staining buffer at a final density of $\geq 5 \times 10^{5}$ cells $/ \mathrm{ml}$. Then, $5 \mu \mathrm{l}$ Annexin V-APC was added into $100 \mu \mathrm{l}$ cell suspensions and incubated at room temperature for 10-15 min. Signals were detected using a Guava EasyCyte HT flow cytometer (EMD Millipore) and InCyte software (version 3.1; EMD Millipore).

Wound healing and Transwell assays. The CytoSelect ${ }^{\mathrm{TM}}$ 96-well Wound Healing Assay (cat. no. CBA-120; Cell Biolabs) was used to analyze migration of $\mathrm{NC}$ and $\mathrm{CapG}$ knockdown cells. After lentiviral infection, cells were incu- bated for $72 \mathrm{~h}$ and then the assay was performed according to the manufacturer's protocol. Briefly, cells were seeded $\left(5 \times 10^{4}\right.$ cells/well $)$ into a 96 -well plate and incubated in medium supplemented with 0.5\% FBS (cat. no. VS500T; Ausbian, Inc.). At $90 \%$ confluence, the wound was created using a scratch tester to align the center of the lower end of the 96-well plate and gently push upward to form a scratch, and detached cells were removed by washing the cells with PBS three times. The wound was observed at 0,3 and $6 \mathrm{~h}$ using an IX71 fluorescence microscope (Olympus Corporation; magnification, x200). The migration rate was calculated as the ratio of the width of the wound at a given time point relative to the width of wound at the $0 \mathrm{~h}$ time point (13).

The Transwell assay was performed using $8-\mu \mathrm{m}$ membrane filter inserts (cat. no. 3422; Corning Inc.), according to the manufacturer's instructions. Briefly, Matrigel (cat no. 356234; BD Biosciences) was dissolved overnight at $4^{\circ} \mathrm{C}$ and diluted with serum free medium (1:3; cat. no. 10-013-CVR; Corning, Inc.). Subsequently, $100 \mu 1$ diluted Matrigel was added to the membrane in the Transwell upper chamber and incubated at $37^{\circ} \mathrm{C}$ for $3 \mathrm{~h}$. Cells $\left(5 \times 10^{4}\right)$ in $0.1 \mathrm{ml}$ serum-free medium were seeded into the upper chamber, whereas the lower chamber consisted of a 24-well plate containing $0.6 \mathrm{ml}$ minimum essential medium supplemented with $30 \%$ FBS. Following incubation for $18 \mathrm{~h}$ at $37^{\circ} \mathrm{C}$ with $5 \% \mathrm{CO}_{2}$, non-invading cells in the upper chamber were carefully removed with a cotton swab and invading cells were fixed with $4 \%$ paraformaldehyde at room temperature for $30 \mathrm{~min}$ and stained with Giemsa (cat. no. 32884; Sigma-Aldrich; Merck KGaA) at room temperature for $5 \mathrm{~min}$. Following washing three times with double distilled $\mathrm{H}_{2} \mathrm{O}$, samples were allowed to air dry. Invading cells were observed using an IX71 fluorescence microscope (Olympus Corporation; magnification, x100).

Microarray processing and analysis. Total RNA from 786-O cells transduced with CapG-siRNA lentivirus or NC lentivirus was extracted using TRIzol reagent. Samples were set up in triplicate. RNA quantity and quality were assessed with a NanoDrop ${ }^{\mathrm{TM}} 2000$ spectrophotometer (NanoDrop Technologies; Thermo Fisher Scientific, Inc.) and Agilent Bioanalyzer 2100 (Agilent Technologies, Inc.). Microarray processing was performed using an Affymetrix Human GeneChip PrimeView (100K array; cat. no. 901838; Affymetrix; Thermo Fisher Scientific, Inc.), according to the manufacturer's instructions. Arrays were scanned using a GeneChip Scanner 3000 to produce the raw data. Significant, differentially expressed genes between 786-O cells treated with CapG-siRNA lentivirus and NC lentivirus were selected based on a threshold of $\mathrm{P}<0.05$ and absolute fold-change $>1.5$ using the 'Affy' package of $\mathrm{R}$ (version 1.46.1; bioconductor. org/packages/release/bioc/html/affy.html). Bioinformatics analysis of the differentially expressed genes was performed using Ingenuity Pathway Analysis (IPA; version 42012434; Qiagen China Co., Ltd.).

Statistical analysis. Quantitative data are presented as the mean \pm standard deviation. A two-way repeated-measures ANOVA followed by Fisher's Least Significant Difference post-hoc test was used to compare the expression of CapG between ccRCC and adjacent normal tissue. All measure- 

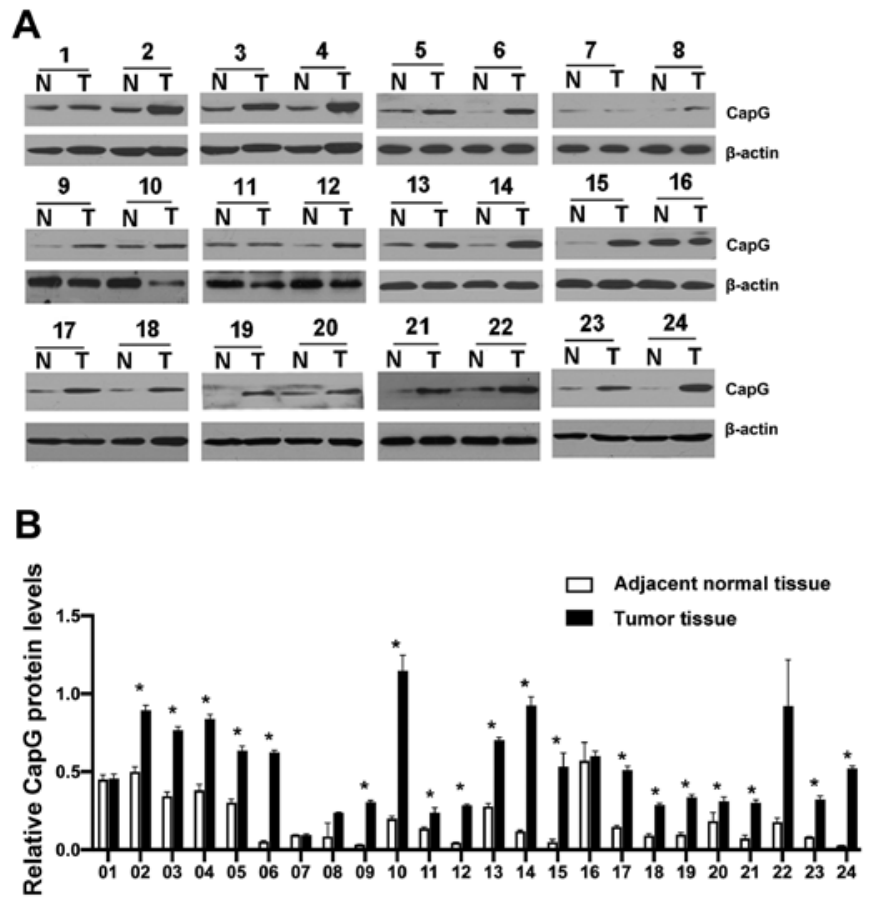

Figure 1. CapG is overexpressed in ccRCC, and predicts a poor prognosis. (A) Western blot analysis of CapG in 24 paired ccRCC and adjacent healthy tissue samples, with $\beta$-actin used as the loading control. (B) Expression levels of CapG, relative to $\beta$-actin levels. ${ }^{*} \mathrm{P}<0.05$ between $\mathrm{T}$ and $\mathrm{N}$ groups. CapG, macrophage capping protein; $\mathrm{T}$, tumor tissue; $\mathrm{N}$, adjacent normal tissue.

ments were repeated three times. One-way ANOVA and Dunnett's post hoc test as were used to analyze the data from functional assays. Categorical variables are presented as count (percentage). The $\chi^{2}$ test was used to analyze the relationship between CapG expression and clinicopathological characteristics. Survival curves were plotted using the Kaplan-Meier method, and compared using the log-rank test. The significance of clinicopathological variables for survival was analyzed using the univariate and multivariate Cox proportional hazards method. All statistical analysis was carried out using the SPSS version 13.0 (SPPS, Inc.). In all analyses, two-tailed $\mathrm{P}<0.05$ was considered to indicate a statistically significant difference.

\section{Results}

CapG expression was elevated in ccRCC tissues, and was closely correlated with clinical outcomes. Western blot analysis was performed to examine CapG protein expression in $24 \mathrm{ccRCC}$ and paired normal renal tissue samples (Fig. 1). Using repeated-measures ANOVA, only the main effect of CapG expression in ccRCC and adjacent normal tissue samples was significant $(\mathrm{P}<0.001)$. The effect of repeated measurements and interaction were not significant $(\mathrm{P}=0.703$ and $\mathrm{P}=0.115$, respectively). $\mathrm{CapG}$ protein expression levels was significantly increased in ccRCC tissue samples, compared with adjacent normal tissue were observed, and most patients (79.17\%; 19/24) displayed significantly higher CapG expression levels in tumor tissue in post-hoc comparisons (all $\mathrm{P}<0.05$ ).

CapG expression was then examined by IHC in 152 ccRCC and 40 normal renal tissue samples. Representative images of CapG IHC staining of ccRCC tissues at different stages and grades, as well as adjacent normal tissues, are presented in Fig. 2. CapG staining was observed both in the cytoplasm
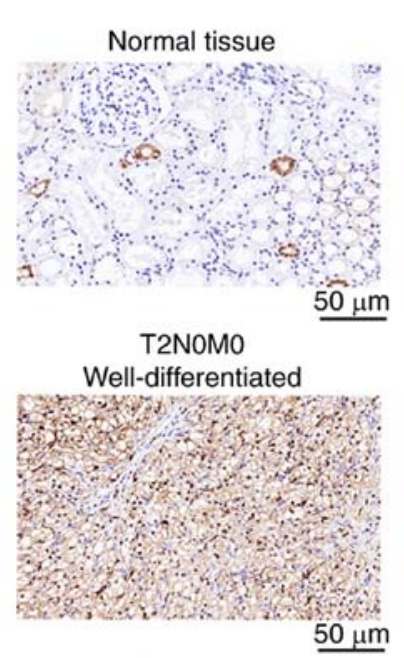

T4N1M0

Poorly differentiated

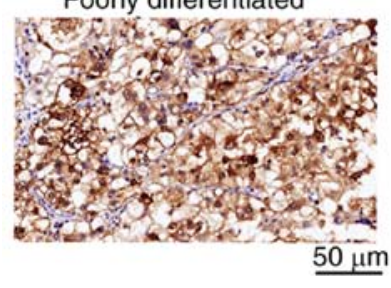

Figure 2. Representative images of CapG immunohistochemical staining in T1NOM0 (grade $1 / 2$, well-differentiated), T2NOM0 (grade $1 / 2$, well-differentiated), T3N0M0 (grade 3, moderately differentiated), T4N1M0 (grade 4 , poorly differentiated) and adjacent healthy tissue samples. Magnification, $\mathrm{x} 200$. CapG, macrophage capping protein.

and nuclear region of the cells. CapG was highly expressed in $7.5 \%$ (3 out of 40 ) of normal tissues, compared with $55.3 \%$ 
Table I. Association between CapG expression levels and clinicopathological variables.

\begin{tabular}{|c|c|c|c|c|c|}
\hline \multirow[b]{2}{*}{ Clinicopathological variable } & \multirow[b]{2}{*}{ Cases, $\mathrm{n}$} & \multicolumn{2}{|c|}{ CapG expression, n (\%) } & \multirow[b]{2}{*}{$\chi^{2}$} & \multirow[b]{2}{*}{ P-value } \\
\hline & & Low & High & & \\
\hline Sex & & & & 3.261 & 0.071 \\
\hline Male & 93 & $47(50.5)$ & $46(49.5)$ & & \\
\hline Female & 59 & $21(35.6)$ & $38(64.4)$ & & \\
\hline Age & & & & 0.869 & 0.351 \\
\hline$<60$ & 89 & 37 (41.6) & $52(58.4)$ & & \\
\hline$\geq 60$ & 63 & $31(49.2)$ & $32(50.8)$ & & \\
\hline pT stage & & & & 10.241 & 0.017 \\
\hline $\mathrm{T} 1$ & 68 & $39(57.4)$ & $29(42.6)$ & & \\
\hline $\mathrm{T} 2$ & 52 & $20(38.5)$ & $32(61.5)$ & & \\
\hline $\mathrm{T} 3$ & 28 & $9(32.1)$ & $19(67.9)$ & & \\
\hline $\mathrm{T} 4$ & 4 & $0(0.0)$ & $4(100.0)$ & & \\
\hline pN stage & & & & 4.316 & 0.038 \\
\hline NO & 131 & $63(48.1)$ & $68(51.9)$ & & \\
\hline $\mathrm{N}+$ & 21 & $5(23.8)$ & $16(76.2)$ & & \\
\hline M stage & & & & 0.336 & 0.562 \\
\hline M0 & 141 & $64(45.4)$ & $77(54.6)$ & & \\
\hline M1 & 11 & $4(36.4)$ & 7 (63.6) & & \\
\hline Tumor grade & & & & 7.081 & 0.029 \\
\hline $1 / 2$ & 51 & $24(47.1)$ & $27(52.9)$ & & \\
\hline 3 & 61 & $33(54.1)$ & $28(45.9)$ & & \\
\hline 4 & 40 & $11(27.5)$ & $29(72.5)$ & & \\
\hline Recurrence & & & & 0.392 & 0.531 \\
\hline Yes & 130 & $60(46.2)$ & $70(53.8)$ & & \\
\hline No & 11 & $4(36.4)$ & 7 (63.6) & & \\
\hline
\end{tabular}

CapG, macrophage capping protein.

(84 of 152) of ccRCC tissue samples $(\mathrm{P}<0.001)$. Moreover, CapG expression was significantly associated with tumor stage $(\mathrm{P}=0.017)$, histological grade $(\mathrm{P}=0.029)$, and lymph node metastasis ( $\mathrm{P}=0.038)$ (Table I). However, $\mathrm{CapG}$ expression was not associated with sex, age, incidence of distant metastasis, or recurrence.

CapG expression predicts prognosis in ccRCC patients. To determine the prognostic value of CapG expression, the association between CapG expression and OS was examined using Kaplan-Meier survival curves and a log-rank test, as well as univariate and multivariate Cox regression models. The 5-year OS rate in patients with high CapG expression was 60.6 and $75.7 \%$ in patients with low expression (log-rank, $6.562, \mathrm{P}=0.010$, Fig. 3A). In addition, the low-expression group displayed significantly higher 1-year OS rate $(98.5$ and $90.5 \%$ in the high and low-expression groups, respectively; $\mathrm{P}=0.043$ ) and 3 -year OS rate (90.8 and 71.4.5\%; $\mathrm{P}=0.004)$, compared with the high-expression group. Moreover, the estimated median survival time was significantly longer in the low-expression group (105 months; 95\% CI, 87.93-122.07) than in the high-expression group (72 months; 95\% CI, 57.37-86-63) $(\mathrm{P}<0.05)$.
To identify clinicopathological variables associated with survival time, univariate analysis of each variable (gender, age, tumor size, $\mathrm{T}$ stage, $\mathrm{N}$ stage, $\mathrm{M}$ stage, tumor grade and CapG expression) was performed. The difference in prognosis prediction is expressed using a hazard ratio (HR) and a $\mathrm{P}$-value. Univariate analysis demonstrated that tumor size, $\mathrm{T}$ stage, $\mathrm{N}$ stage, $\mathrm{M}$ stage, tumor grade, and CapG expression levels were significant predictors of OS. The relative importance of each of these variables was then determined using a multivariate Cox proportional hazards analysis. Multivariate analysis showed that $\mathrm{T}$ stage, $\mathrm{N}$ stage, $\mathrm{M}$ stage, and $\mathrm{CapG}$ expression level were independent predictors of OS. Patients with high CapG expression had a 2.12-time higher risk than those with low expression (HR, 2.121; 95\% CI, 1.288-3.493; P=0.003) (Table II).

CapG expression is efficiently inhibited by lentivirus-based siRNA knockdown in 786-O cells. CapG mRNA levels were effectively decreased in 786-O cell treated with CapG-specific siRNA, compared with the control scramble NC control (Fig. 3B). Since knockdown efficiency following siRNA1 transfection was $95.4 \%$, this siRNA was used in subsequent experiments. 
Table II. Univariate and multivariate Cox proportional hazards model for overall survival in 152 patients with clear cell renal cell carcinoma.

\begin{tabular}{|c|c|c|c|c|c|c|}
\hline \multirow[b]{2}{*}{ Clinicopathological variable } & \multicolumn{3}{|c|}{ Univariate analysis } & \multicolumn{3}{|c|}{ Multivariate analysis } \\
\hline & HR & $95 \% \mathrm{CI}$ & P-value & HR & $95 \%$ CI & P-value \\
\hline Sex (female vs. male) & 1.084 & $0.692-1.700$ & 0.724 & - & - & - \\
\hline Age $\geq 60$ vs. $<60$ & 1.167 & $0.749-1.818$ & 0.496 & - & - & - \\
\hline Tumor size, $\mathrm{cm}(>7.0 \mathrm{vs} . \leq 7.0)$ & 2.322 & $1.478-3.648$ & $<0.001$ & 1.757 & $0.896-3.446$ & 0.101 \\
\hline pT stage & - & - & 0.001 & - & - & 0.018 \\
\hline $\mathrm{T} 2$ vs. T1 & 1.459 & $0.854-2.492$ & 0.167 & 0.690 & $0.331-1.435$ & 0.320 \\
\hline $\mathrm{T} 3$ /T4 vs. T1 & 3.044 & $1.743-5.317$ & $<0.001$ & 1.672 & $0.841-3.325$ & 0.143 \\
\hline pN stage (N+ vs. N0) & 4.995 & $2.928-8.522$ & $<0.001$ & 4.712 & $2.465-9.006$ & $<0.001$ \\
\hline M stage (M1 vs. M0) & 7.433 & $3.673-15.042$ & $<0.001$ & 7.284 & $3.224-16.445$ & $<0.001$ \\
\hline Tumor grade & - & - & $<0.001$ & - & - & 0.131 \\
\hline 3 vs. $1 / 2$ & 1.504 & $0.837-2.702$ & 0.173 & 1.219 & $0.644-2.309$ & 0.543 \\
\hline 4 vs. $1 / 2$ & 4.863 & $2.733-8.653$ & $<0.001$ & 1.997 & $0.968-4.123$ & 0.061 \\
\hline CapG expression (high vs. low) & 1.827 & $1.142-2.922$ & 0.012 & 2.121 & $1.288-3.493$ & 0.003 \\
\hline
\end{tabular}

CapG, macrophage capping protein; HR, hazard ratio.
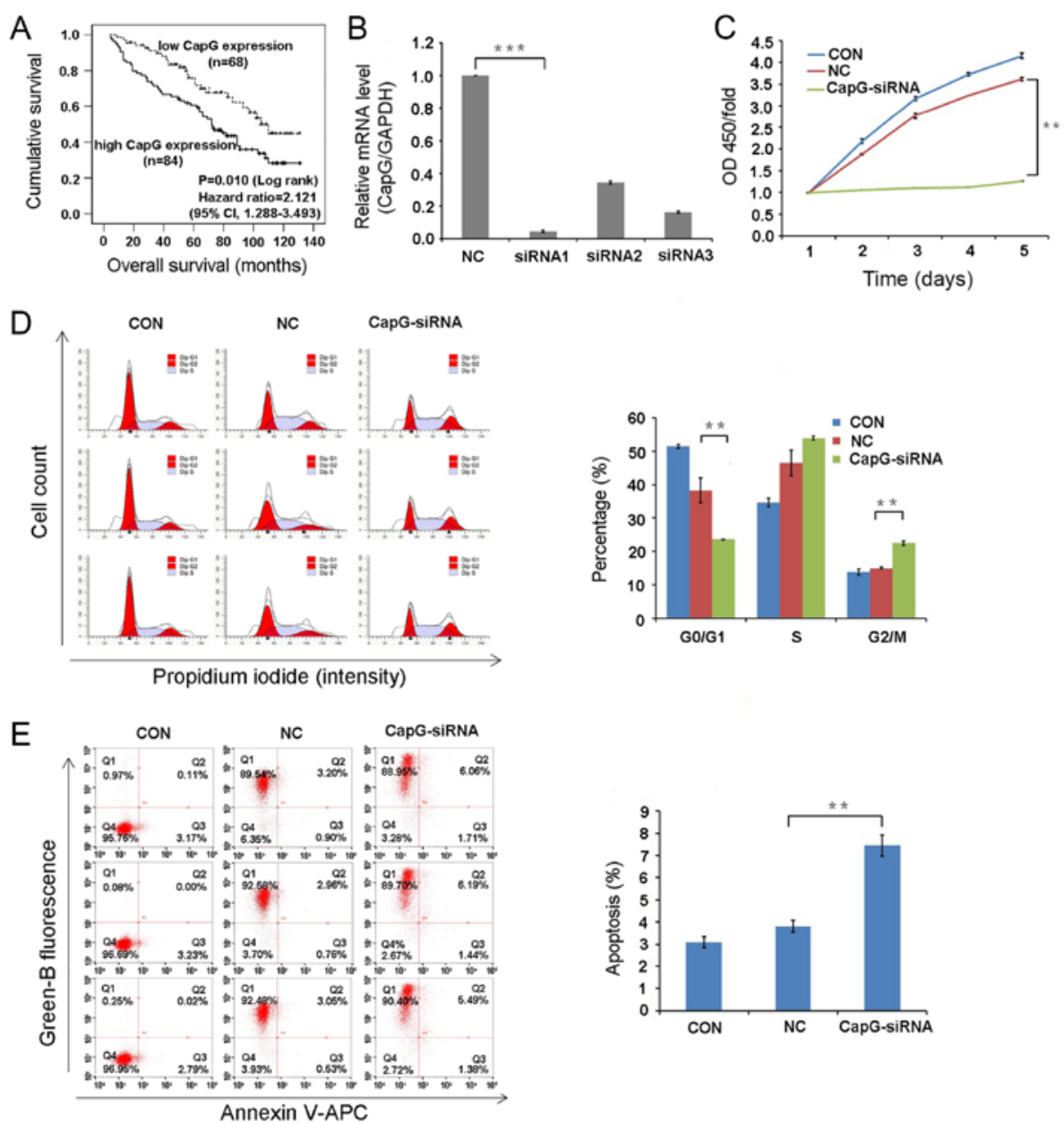

Figure 3. Comparison of overall survival and CapG knockdown in 786-O cells. (A) Overall survival in patients with high or low CapG expression. (B) Reverse transcription-quantitative PCR analysis of CapG expression in 786-O cells following transfection with CapG-siRNA or NC. (C) Cell proliferation rate in 786-O cells transfected with CapG-siRNA or NC, as determined using a Cell Counting Kit- 8 assay. (D) CapG knockdown induces $\mathrm{G}_{2} / \mathrm{M}_{\text {phase }}$ arrest. (E) CapG knockdown results in increased cell apoptosis. Data are presented as the mean $\pm \mathrm{SD} .{ }^{* *} \mathrm{P}<0.01 ;{ }^{* * *} \mathrm{P}<0.001$ (Dunnett's post hoc test). CapG, macrophage capping protein; NC, negative control; siRNA, small interfering RNA; con, control; OD, optical density; APC, allophycocyanin; CI, confidence interval. 

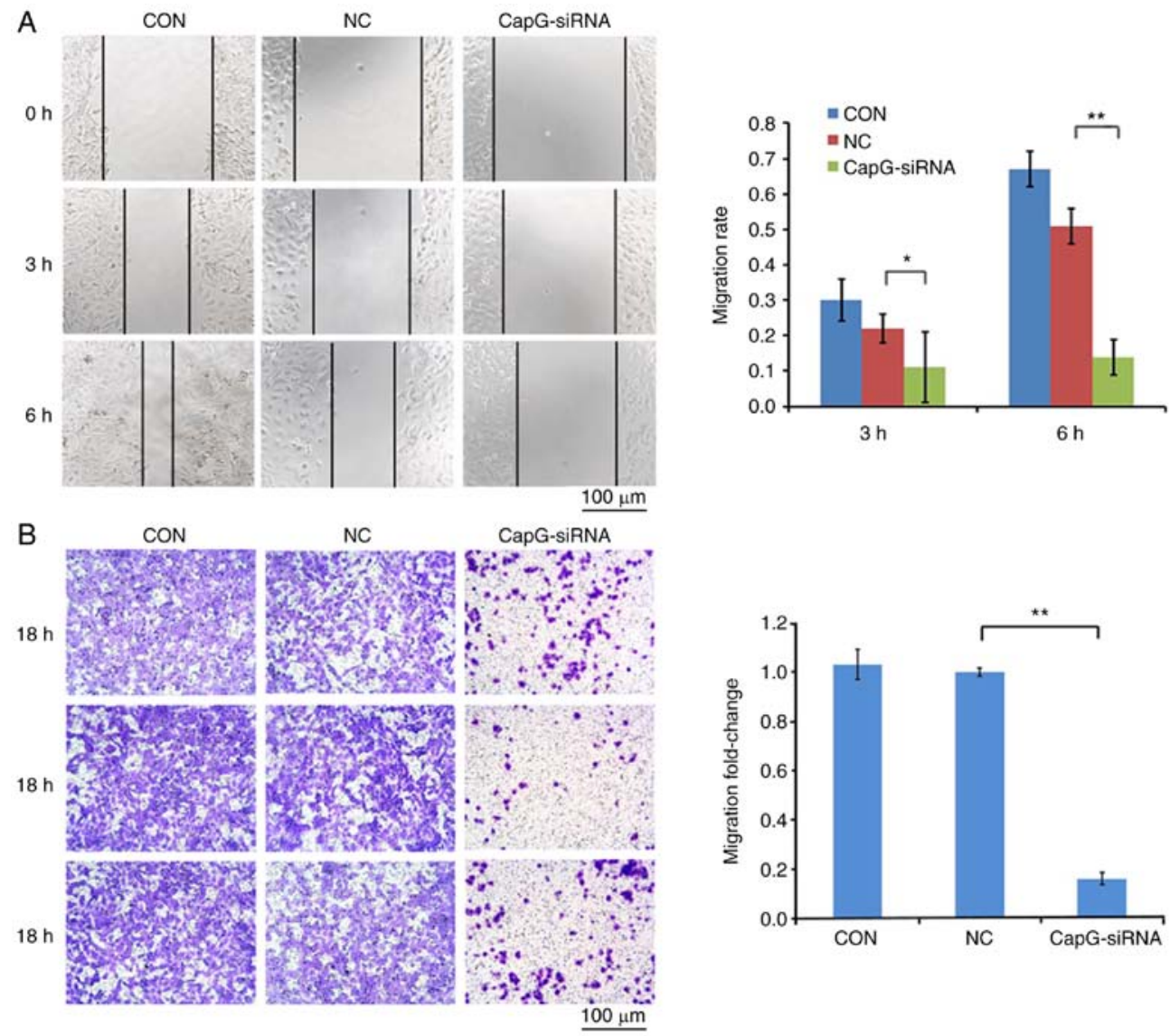

Figure 4. CapG knockdown inhibits migration and invasion of 786-O cells. (A) Representative images of wound healing assays as 0,3 and $6 \mathrm{~h}$. Magnification, x200. Migration rate is defined as: migration distance/width of open wound at $0 \mathrm{~h}$. (B) Effect of CapG knockdown on the invasion of 786-O cells, as evidenced by a Transwell assay. Magnification, $\mathrm{x} 100 .{ }^{*} \mathrm{P}<0.05 ;{ }^{* *} \mathrm{P}<0.01$. CapG, macrophage capping protein; NC, negative control; siRNA, small interfering RNA; con, control.

Cell proliferation is impaired by CapG knockdown. The effect of CapG knockdown on 786-O cell proliferation was determined using a CCK-8 cell proliferation assay. The proliferation rate in the CapG-siRNA group was significantly reduced, compared with the NC group $(\mathrm{P}<0.01$; Fig. $3 \mathrm{C})$. Thus, CapG knockdown suppresses the proliferation of human ccRCC cells in vitro.

CapG knockdown induces cell cycle arrest and apoptosis. Cell cycle progression and apoptosis were analyzed by flow cytometry. Cell cycle distribution in the untransduced control (CON) group was: i) $\mathrm{G}_{0} / \mathrm{G}_{1}, 51.56 \%$; ii) $\mathrm{S}, 34.62 \%$; and iii) $\mathrm{G} 2 / \mathrm{M}, 13.82 \%$. The distribution in the $\mathrm{NC}$ group was: i) $\mathrm{G}_{0} / \mathrm{G}_{1}, 38.40 \%$; ii) $\mathrm{S}, 46.58 \%$; and iii) $\mathrm{G}_{2} / \mathrm{M}, 15.03 \%$. The distribution in the CapG-siRNA group was: i) G0/G1, 23.54\%; ii) S, 54.04\%; and iii) $\mathrm{G}_{2} / \mathrm{M}, 22.43 \%$. Overall, the CapG-siRNA group displayed a significant decrease in $G_{0} / G_{1}$ phase cells, and a significant increase in $G_{2} / M$ phase cells $(P<0.01$ in both cases). These findings indicate that $\mathrm{CapG}$ silencing induces cell cycle arrest at the $\mathrm{G}_{2} / \mathrm{M}$ phase and that CapG affects cell cycle distribution.

Furthermore, the percentage of apoptotic 786-O cells significantly increased in the CapG-siRNA group, compared with the NC group $(7.43 \pm 0.49 \%$ vs. NC $3.81 \pm 0.26 \%$, respectively; $\mathrm{P}<0.01$; Fig. 3E). These results suggest that $\mathrm{CapG}$ is associated with apoptosis of ccRCC cells.
Knockdown of CapG inhibited tumor cell migration and invasion. A wound healing assay and a Transwell Matrigel ${ }^{\mathrm{TM}}$ assay were carried out to evaluate the influence of $\mathrm{CapG}$ on cell migration and invasion, respectively, of 786-O cells. Microscopic analysis indicated that CapG-silenced cells migrated faster than cells transduced with NC lentivirus after $3 \mathrm{~h}(\mathrm{P}<0.05)$ and $6 \mathrm{~h}(\mathrm{P}<0.01)($ Fig. 4A), indicating the migration ability of 786-O cells was significantly inhibited by CapG silencing. Moreover, in the Transwell Matrigel ${ }^{\mathrm{TM}}$ assay, downregulation of CapG suppressed the invasion ability of ccRCC cells (Fig. 4B). Altogether, these findings suggest that CapG plays a crucial role in migration and invasion of ccRCC cells.

Disruption of critical pathways involved in cancer development by CapG knockdown. The aforementioned results indicate that $\mathrm{CapG}$ is critical for migration and invasion of ccRCC cells. However, the mechanisms underlying the role of CapG and downstream pathways in ccRCC have not been explored. In this study, global gene expression profiles of 786-O cells transduced with CAPG-siRNA lentivirus or NC lentivirus were examined using a microarray platform. A total of 510 genes showing significant differential expressions were identified, including 179 upregulated genes and 331 downregulated genes (Fig. 5A). IPA demonstrated that the differentially expressed genes were enriched in canonical pathways, and were therefore sorted according to their $-\log (\mathrm{P}$-value $)$. Some 

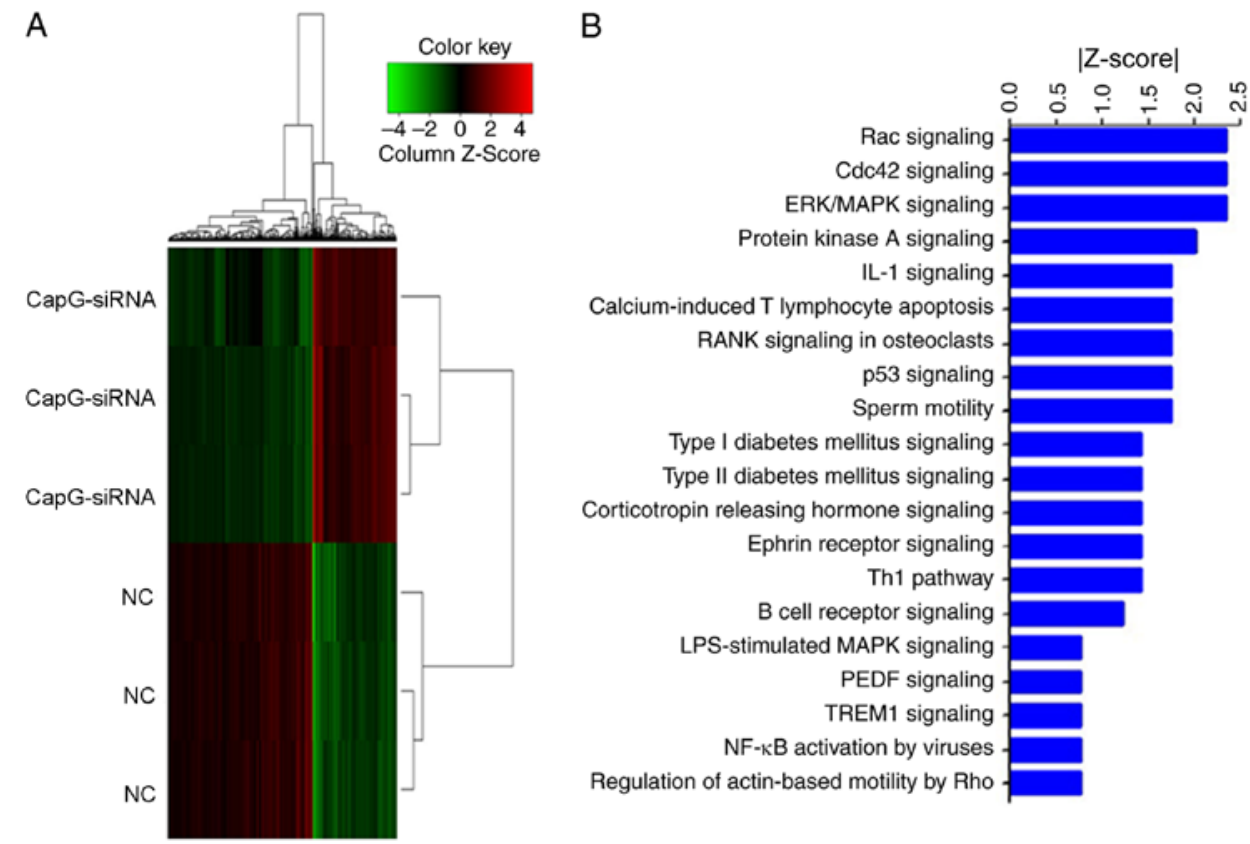

Figure 5. Widespread changes of gene expressions in 786-O cells with CapG knockdown by microarray analysis. (A) Heatmap representation of 510 genes with significant differential expression in 786-O cells transduced with CapG-siRNA lentivirus or NC lentivirus. Red color represents upregulation and green represents downregulation). $\mathrm{P}<0.05$ and Ifold-changel $>1.5$ were used as criteria for differentially expressed genes. Each sample was processed in triplicate. (B) Functional pathway enrichment of differentially expressed genes was analyzed using Ingenuity Pathway Analysis. The IZ-scorel is displayed on the y-axis. $\mid Z$-scorel $>2$ indicates enriched signaling pathways that are significantly activated or inhibited.CapG, macrophage capping protein.

of the pathways were significantly inhibited (Z-score $<-2)$, including 'Rac signaling', 'CDC42 signaling', 'ERK/MAPK signaling' and 'PKA signaling' (Fig. 5B).

\section{Discussion}

ccRCC is one of the most common and aggressive types of RCC. While chemotherapy and radiotherapy are ineffective, targeted therapies can improve the outcomes of patients with ccRCC (14). Therefore, identification of the molecular mechanisms involved in ccRCC pathogenesis is critical for the development innovative therapeutic strategies.

CapG was originally identified in the cytoplasm of alveolar macrophages and is involved in cell motility and membrane ruffling. CapG overexpression has been reported in several types of cancer, including pancreatic, breast and gastric cancer (9-11). However, the association of CapG with clinical characteristics and prognosis in ccRCC has not been studied. In the present study, CapG expression was increased in ccRCC tissue, compared with normal tissue. In addition, CapG expression levels were associated with tumor stage, histological grade, and lymph node metastasis. Moreover, CapG was associated with poor prognosis and was an independent predictor of OS in ccRCC. Consistent with our findings, CapG is upregulated in patients with stage-III serous ovarian adenocarcinoma, and high expression of CapG is correlated with shorter survival (15). Furthermore, high CapG expression has been found to be a unfavorable prognostic factor in prostate cancer (16) and glioma (17). Collectively, these studies suggest that CapG may represent a novel prognostic marker for ccRCC.

In the present study, CapG knockdown significantly inhibited ccRCC cell proliferation in vitro and induced $\mathrm{G}_{2} / \mathrm{M}$ arrest.
Supporting our findings, recent studies have indicated that CapG downregulation suppressed cell proliferation in prostate cancer (16) and human glioma (17) in vitro. It was also observed that CapG knockdown attenuated the migration and invasion of ccRCC cells. Consistent with the present study, CapG knockdown is known to inhibit the migration of invasive breast cancer cells (10), the invasion of gastric cancer cells (11), and the migration and invasion of glioma cells (17). The present findings also suggested that CapG might promote metastasis in ccRCC and could represent a target against ccRCC metastasis.

CapG is localize to both the nucleus and cytoplasm, and increased levels in nuclear CapG promote cell invasion (18). It has been demonstrated that nuclear CapG can interfere with nuclear PI3-kinase (19). This suggests that CapG may be involved in PI-driven chromatin remodeling (20) and could therefore play a role as a regulator of gene transcription. Moreover, CapG could also act on gene transcription by directly binding to DNA, as indicated by the presence of a c-Myc-like DNA-binding domain (21). A recent study has demonstrated that CapG enhances breast cancer metastasis through competition with transcriptional repressor arginine methyltransferase 5 for binding to the STC-1 promoter, leading to reduced histone H4R3 methylation and enhanced STC-1 transcription (22). Our microarray analysis demonstrated that 510 genes were significantly differentially expressed in CapG-knockdown cells. The differentially expressed genes were enriched in canonical signaling pathways, such as RAC, CDC42 and ERK/MAPK signaling, which might be critical for ccRCC development and progression.

CapG is a member of the gelsolin family. Notably, gelsolin has also been shown to participate in cancer development (23). Visapää et al (24) have reported that decreased gelsolin 
expression in RCC is associated with a poor patient survival. Additionally, an in vitro study suggested that overexpression of gelsolin inhibits the proliferation, adhesion, and invasion ability of 786-O ccRCC cells, indicating a tumor-suppressor role (25). By contrast, Kankaya et al (26) have proposed that gelsolin expression is correlated with high nuclear grade, metastasis, late stage, and cancer death in RCC, suggesting an oncogenic function. These findings suggested that the biological function of gelsolin in tumorigenesis of RCC remains inconclusive. Nevertheless, as the present study demonstrated that $\mathrm{CapG}$ played a tumorigenic role in ccRCC, possible connections between gelsolin and CapG in renal cancer should be evaluated.

To the best of our knowledge, the present study is the first to suggest that CapG is upregulated in ccRCC, and is associated with advanced tumor stage, histological grade, lymph node metastasis, and poor overall survival. Moreover, CapG is an independent predictor of OS in ccRCC. CapG silencing also inhibits renal carcinoma cell proliferation, migration, and invasion. Taken together, these results suggest that CapG may be an effective biomarker and a potential therapeutic target for ccRCC.

\section{Acknowledgements}

Not applicable.

\section{Funding}

This work was financially supported by President Foundation of Nanfang Hospital, Southern Medical University (grant no. 2019B022).

\section{Availability of data and materials}

The datasets used and/or analyzed during the current study are available from the corresponding author on reasonable request.

\section{Authors' contributions}

TC and ZFC designed the study. ZFC, ZHH, SJC and YDJ performed all of the assays and participated in data analysis. ZFC wrote the manuscript. SBZ and ZKQ took part in analysis and interpretation of the data, and edited the manuscript. All authors reviewed the manuscript for important intellectual content. All authors read and approved the final manuscript.

\section{Ethics approval and consent to participate}

Ethical approval was obtained by Nanfang Hospital, Southern Medical University. All participants signed informed consent at the time of clinical intervention with knowledge that their data and materials may be used for research purposes.

\section{Patient consent for publication}

Not applicable.

\section{Competing interests}

The authors declare that they have no competing interests.

\section{References}

1. Hsieh JJ, Purdue MP, Signoretti S, Swanton C, Albiges L, Schmidinger M, Heng DY, Larkin J and Ficarra V: Renal cell carcinoma. Nat Rev Dis Primers 3: 17009, 2017.

2. Ross K and Jones RJ: Immune checkpoint inhibitors in renal cell carcinoma. Clin Sci (Lond) 131: 2627-2642, 2017.

3. Dabestani S, Thorstenson A, Lindblad P, Harmenberg $\mathrm{U}$, Ljungberg $\mathrm{B}$ and Lundstam S: Renal cell carcinoma recurrences and metastases in primary non-metastatic patients: A population-based study. World J Urol 34: 1081-1086, 2016.

4. Motzer RJ, Escudier B, McDermott DF, George S, Hammers HJ Srinivas S, Tykodi SS, Sosman JA, Procopio G, Plimack ER, et al; CheckMate 025 Investigators: Nivolumab versus everolimus in advanced renal-cell carcinoma. N Engl J Med 373: 1803-1813, 2015.

5. Lei C, Lv S, Wang H, Liu C, Zhai Q, Wang S, Cai G, Lu D, Sun Z and Wei Q: Leukemia inhibitory factor receptor suppresses the metastasis of clear cell renal cell carcinoma through negative regulation of the yes-associated protein. DNA Cell Biol 37: 659-669, 2018.

6. Chen ZF, Xiao YJ, Huang ZH, Chen T, Zhao SC, Jiang YD, Wu P and Zheng SB: Quantitative and comparative proteomics analysis in clear cell renal cell carcinoma and adjacent noncancerous tissues by 2-D DIGE. Nan Fang Yi Ke Da Xue Xue Bao 37: 1517-1522, 2017 (In Chinese)

7. Silacci P, Mazzolai L, Gauci C, Stergiopulos N, Yin HL and Hayoz D: Gelsolin superfamily proteins: Key regulators of cellular functions. Cell Mol Life Sci 61: 2614-2623, 2004.

8. Yu FX, Johnston PA, Südhof TC and Yin HL: gCap39, a calcium ion- and polyphosphoinositide-regulated actin capping protein. Science 250: 1413-1415, 1990.

9. Thompson CC, Ashcroft FJ,Patel S, Saraga G, Vimalachandran D, Prime W, Campbell F, Dodson A, Jenkins RE, Lemoine NR, et al: Pancreatic cancer cells overexpress gelsolin family-capping proteins, which contribute to their cell motility. Gut 56: 95-106, 2007.

10. Renz M, Betz B, Niederacher D, Bender HG and Langowski J: Invasive breast cancer cells exhibit increased mobility of the actin-binding protein CapG. Int J Cancer 122: 1476-1482, 2008.

11. Ichikawa H, Kanda T, Kosugi S, Kawachi Y, Sasaki H, Wakai T and Kondo T: Laser microdissection and two-dimensional difference gel electrophoresis reveal the role of a novel macrophage-capping protein in lymph node metastasis in gastric cancer. J Proteome Res 12: 3780-3791, 2013.

12. Livak KJ and Schmittgen TD: Analysis of relative gene expression data using real-time quantitative PCR and the $2-\Delta \Delta \mathrm{CT}$ method. Methods 25: 402-408, 2001.

13. Chen Z, Xiao K, Chen S, Huang Z, Ye Y and Chen T: Circular RNA hsa circ 001895 serves as a sponge of microRNA-296-5p to promote clear cell renal cell carcinoma progression by regulating SOX12. Cancer Sci 111: 713-726, 2020.

14. Kitamura H, Takahashi A, Takei F, Hotta H, Miyao N, Shindo T, Igarashi M, Tachiki H, Kunishima Y, Muranaka T, et al; Sapporo Medical University Urologic Oncology Consortium: Molecular-targeted therapy and surgery may prolong survival of renal cell carcinoma patients with bone metastasis: a multi-institutional retrospective study in Japan. Anticancer Res 36: 5531-5536, 2016.

15. Partheen K, Levan K, Osterberg L, Claesson I, Fallenius G, Sundfeldt K and Horvath G: Four potential biomarkers as prognostic factors in stage III serous ovarian adenocarcinomas. Int J Cancer 123: 2130-2137, 2008.

16. Li T, Hong X, Zhao J, Teng Y, Zheng J, Chen H, Chen $\mathrm{H}$ and $\mathrm{Li} \mathrm{H}$ : Gelsolin-like actin-capping protein is associated with patient prognosis, cellular apoptosis and proliferation in prostate cancer. Biomarkers Med 10: 1251-1260, 2016.

17. Yun DP, Wang YQ, Meng DL, Ji YY, Chen JX, Chen HY and Lu DR: Actin-capping protein CapG is associated with prognosis, proliferation and metastasis in human glioma. Oncol Rep 39: 1011-1022, 2018.

18. De Corte V, Van Impe K, Bruyneel E, Boucherie C, Mareel M, Vandekerckhove J and Gettemans J: Increased importin-beta-dependent nuclear import of the actin modulating protein CapG promotes cell invasion. J Cell Sci 117: 5283-5292, 2004.

19. Lu PJ, Hsu AL, Wang DS, Yan HY, Yin HL and Chen CS: Phosphoinositide 3-kinase in rat liver nuclei. Biochemistry 37: 5738-5745, 1998. 
20. Steger DJ, Haswell ES, Miller AL, Wente SR and O'Shea EK: Regulation of chromatin remodeling by inositol polyphosphates. Science 299: 114-116, 2003.

21. Pellieux C, Desgeorges A, Pigeon $\mathrm{CH}$, Chambaz C, Yin $\mathrm{H}$, Hayoz D and Silacci P: Cap G, a gelsolin family protein modulating protective effects of unidirectional shear stress. J Biol Chem 278: 29136-29144, 2003.

22. Huang S, Chi Y, Qin Y, Wang Z, Xiu B, Su Y, Guo R, Guo L, Sun $\mathrm{H}$, Zeng $\mathrm{C}$, et al: $\mathrm{CAPG}$ enhances breast cancer metastasis by competing with PRMT5 to modulate STC-1 transcription. Theranostics 8: 2549-2564, 2018.

23. Kim HL, Seligson D, Liu X, Janzen N, Bui MHT, Yu H, Shi T, Figlin RA, Horvath $\mathrm{S}$ and Belldegrun AS: Using protein expressions to predict survival in clear cell renal carcinoma. Clin Cancer Res 10: 5464-5471, 2004.
24. Visapää H, Bui M, Huang Y, Seligson D, Tsai H, Pantuck A, Figlin R, Rao JY, Belldegrun A, Horvath S, et al: Correlation of $\mathrm{Ki}-67$ and gelsolin expression to clinical outcome in renal clear cell carcinoma. Urology 61: 845-850, 2003.

25. Zhu X, Cai L, Meng Q and Jin X: Gelsolin inhibits the proliferation and invasion of the 786-0 clear cell renal cell carcinoma cell line in vitro. Mol Med Rep 12: 6887-6894, 2015.

26. Kankaya D, Kiremitci S, Tulunay O and Baltaci S: Gelsolin, $\mathrm{NF}-\kappa \mathrm{B}$, and $\mathrm{p} 53$ expression in clear cell renal cell carcinoma: Impact on outcome. Pathol Res Pract 211: 505-512, 2015.

This work is licensed under a Creative Commons Attribution-NonCommercial-NoDerivatives 4.0 International (CC BY-NC-ND 4.0) License. 